\title{
深海海洋生态系统与海洋生态保护区发展趋势
}

\author{
谢伟 ${ }^{1,2}$, 殷克东 ${ }^{1,2}$ \\ (1. 中山大学海洋科学学院, 广东珠海 519082；2. 南方海洋科学与工程广东省实验室（珠海）, 广东珠海 519082)
}

摘要: 本文介绍了深海生态系统的类型及研究现状、面临的主要问题、关键需求及对策。与浅海生态系统相比, 深海样品获 取困难、已知数据少、研究程度较低。深海栖息着丰富多彩的生物群落, 例如深海热泉中分布的具有特化营养体的管状蠕虫 及极端嗜热古菌、冷泉区分布的硫酸盐还原菌共生的贻贝及蛤类、海山区域高度多样性的生物群落、捕食浮游生物的冷水珊 瑚以及形态奇特的深洲狮子鱼, 这些均迥异于其他生态环境, 具有很高的生态研究价值。近年来, 我国对深海资源的开发需 求日益增强, 深海探测技术迅速发展为深海生态系统的研究提供了契机, 开展深海生物多样性研究并发展深海生态系统理论 模型, 成为迫在眉睫且切实可行的重要任务。为此, 提出建立深海生物数据库、平衡深海资源利用与生态保护的关系、发展 深海生态理论模型、加快管理对策和法律文书的制定等深海生态系统的保护对策建议。

关键词: 生物多样性; 深海生态系统; 海洋生态保护区

中图分类号: S931 文献标识码: A

\section{Development Trend of Deep-Sea Ecosystem and Marine Protected Areas}

\author{
Xie Wei ${ }^{1,2}$, Yin Kedong ${ }^{1,2}$ \\ (1. School of Marine Science, Sun Yat-Sen University, Zhuhai 519082, Guangdong, China; \\ 2. Southern Marine Science and Engineering Guangdong Laboratory (Zhuhai), Zhuhai 519082, Guangdong, China)
}

\begin{abstract}
The types, current situation, main problems, and technological needs of deep-sea ecosystems are described in this paper. Compared with those of shallow-sea ecosystems, samples of deep-sea ecosystems are more difficult to get, accumulated data is less, and the research degree is relatively limited. Diverse species dwell in deep sea, for example, the tubeworms and extemothermophilic archaea around the deep-sea hydrothermal vents, the mussels and clams that live on those sulfate reducing bacteria in the cold spring zone, the diverse species in the seamounts, the cold-water coral that capture the planktons, and the specialized sailfish in abyss. Those ecosystems are quite different from others and have high values for study. Recently, the rapid development of the deep-sea monitoring equipment and other detection devices provides a golden opportunity for studying the deep-sea ecosystems. The researches of the biodiversity and ecological theory for deep-sea ecosystems are urgent and practical. Therefore, strategies for protecting the deepsea ecosystem are proposed, including: to build a database of the deep-sea biology; to balance the deep-sea mineral exploring and ecosystem protection; to develop the theory model for deep-sea ecosystem; and to accelerate the formulation of management strategies and legal instruments.
\end{abstract}

Keywords: biodiversity; deep-sea ecosystems; marine protected areas

收稿日期 : 2019-08-03; 修回日期 : 2019-10-09

通讯作者 : 谢伟, 中山大学海洋科学学院副教授, 主要研究方向为海洋古菌生态学; E-mail: xiewei9@mail.sysu.edu.cn

资助项目：中国工程院咨询项目 “海洋强国战略研究 2035” (2018-ZD-08)

本刊网址 : www.engineering.org.cn/ch/journal/sscae 


\section{一、前言}

水深大于 $200 \mathrm{~m}$ 的海洋大约占世界海洋水体的 95\%, 主要包括陆坡、洋脊、洋盆和海沟等区域。 深海海底富含多金属结核、多金属结壳、硫化物矿 床和铁锰结壳等矿藏。随着陆地资源的迅速消耗, 人类的眼光开始转向海洋。由于深海开采技术的飞 速发展和成本下降, 深海开采的经济性已成为可能。 尽管深海生物的代谢作用和生长相对较慢, 但深海 生态系统是地球上最大的生物栖息地, 其生物多样 性（基因多样性、物种多样性、群落多样性和生态 系多样性）极高, 是新型生物资源的宝库。开发利 用深海资源，同时保护深海生物多样性及生态系统 不遭受破坏，是摆在决策者面前的重大难题。

\section{二、深海生态系统类型及研究现状}

深海中的大部分区域压力大、食物少、没有光 线等，是营养贵乏的 “荒漠”，在这个广哀的 “荒 漠”之中, 也存在一些 “生命绿洲”, 如深海热液区、 冷泉区、深海冷水珊瑚区、海山区、深洣区等特殊 的生态环境, 这些生态系统具有与海洋上层不同的 生物种类、生物群落和生态关联方式, 具有重要的 生态研究价值。

\section{（一）深海热液区生态系统}

海洋科学家于 1977 年在东太平洋加拉帕戈斯 群岛发现了深海热液 [1], 这一发现引发了人们对 于 “生命起源于深海热液区” 的讨论 $[2,3]$, 是生命 科学上的最重要发现之一。深海热液区具有地球其 他地方没有的物种, 目前已发现的就有 550 种 [4]。 深海热液区的这些生物形成独特的深海生命方式, 存在完全不依赖于光合作用而独立生存的独立生命 体系, 初级生产者是丰度极高的不需要阳光支持的 化能自养微生物, 次级生产者包括成簇的管状蠕虫、 贻贝、蟹类和鱼类 (见图 1) [5,6]。热液口区围绕 在洋中脊周边, 海水穿过洋壳冷却过程中形成的裂 隙而被加热, 温度可高达 $350 \sim 400{ }^{\circ} \mathrm{C}$, 由于热液密 度相对海水密度较小, 会穿过海底岩层上涌, 在海 水混合过程中，热液中的多种黑色金属硫化物发生 沉积作用, 在喷溢口的周围连续沉淀, 不断加高, 形成 “黑烟图” [7]。热液之中含有大量的硫化氢,
这对于大多数生物而言是有毒的, 但却是部分化能 自养微生物的 “美食”。有些热液口的动物是通过 从水体中过滤这些菌体来捕食, 而另一些动物是通 过与这些微生物共生的方式来生活。如热液口占优 势地位的大型管状蠕虫, 它不用过滤捕食, 而是进 化形成了一个高度特异化的器官, 称为摄食体, 里 面就包含了大量的共生微生物, 这些共生微生物在 蠕虫体内进行化能自养作用，并将它制造的有机物 质直接供给其宿主。共生微生物有时能占到蠕虫营 养体 $25 \%$ 以上的体积 $[8,9]$ 。这种管状蠕虫是热液口 特有物种中的典型代表，具有较高的科研价值。同 时, 热液口还蕴含着丰富的嗜热古菌资源, 如分离 自太平洋底部 $2400 \mathrm{~m}$ 深处的 “Strain 121” 古菌, 是 目前有报道的生长温度最高的生物, 该菌株能够在 温度高达 $121{ }^{\circ} \mathrm{C}$ 的高压灭菌器中, 以甲酸盐作为电 子供体, 以三价铁作为电子受体继续生长繁殖 [10]。 该菌株的发现表明了在热液口这样的极端环境下, 这些嗜热微生物可能已经进化出一套非常有效的耐 热机制。对于深海热泉嗜热菌的研究, 很可能拓展 人们对生命极限适应温度的认知。随着高通量测序 技术的发展, 为揭示深海热液口微生物群落的适应 性机制提供了机遇, 笔者前期比较分析了胡安德富 卡硫化物 “黑烟图”与大西洋中部的称为 “迷失之 城” 的碳酸盐 “白烟图” 的微型生物宏基因组序列, 发现尽管矿物组成不同, 但两个热液口微生物群落 均表现出高丰度的 DNA 修复相关的基因, 表明这 些微生物需要进化出较强的 DNA 修复系统来应对 热液口高温、金属离子、毒性化合物等恶劣条件对 DNA 的损伤; 但在氮代谢方面, 两种热液环境的 微生物群落又呈现出显著不同的特征, 硫化物 “黑 烟图” 含有丰度较高的反硝化相关的基因，而 “白 烟图” 反硝化相关基因含量则较少 [11]，这一结果 与之后的原位化学方法测定结果一致 [12], 揭示了 不同热液口微生物群落生态功能的差异性。这些研 究结果均展现出热液区在深海生态系统中的独特性 和重要性。

\section{（二）深海冷泉生态系统}

在海底沉积界面之下的以水、碳氢化合物、硫 化氢、细粒沉积物为主要成分的流体以喷涌或渗漏 方式从海底溢出, 并产生系列的物理、化学及生物 作用, 这种作用及其产物称为冷泉。目前在全球大 
陆边缘发现的冷泉活动区有上千个 [13]。冷泉的温 度与海底周围温度基本一致, 由于溢出的流体富含 甲烷、硫化氢等组分, 能够给一些化能自养合成的 细菌和古菌提供丰富的养分。这些甲烷古菌主要是 甲烷氧化类群, 在冷泉中占有很高的数量, 是冷泉 生态系统的食物链基础, 它们分布于硫酸盐 - 甲烷 转换带, 形成数厘米至数米甚至数百米的菌斑, 这 些微生物对于冷泉流体的位置和规模均有较强的指 示意义 [14]。在硫酸盐还原细菌和甲烷氧化微生物 参与下, 冷泉流体中的甲烷会发生厌氧氧化反应, 而硫酸盐还原细菌释放的硫化氢则可成为给化能自
养微生物提供能量和物质的来源, 从而供应冷泉生 物群的食物基础, 并繁衍成独特的冷泉生态系统 ( 见 图 2)。根据对内共生化能自养细菌的依附程度, 可 将冷泉生态群落划分为专性种 (如菌席、贻贝类、 管状蠕虫和蛤类等)、潜在专性种（如腹足动物、 帽贝和螃蟹等) 和非专性种 (如海葵、腹足动物、 短尾亚目甲壳动物等） [15]。冷泉生物具有极高的 生物密度和独特的生物多样性, 孕育着丰富基因资 源和独特的有潜在利用价值的代谢产物, 这些都为 生物学家发现新的微生物代谢途径和生存对策提供 了机遇。

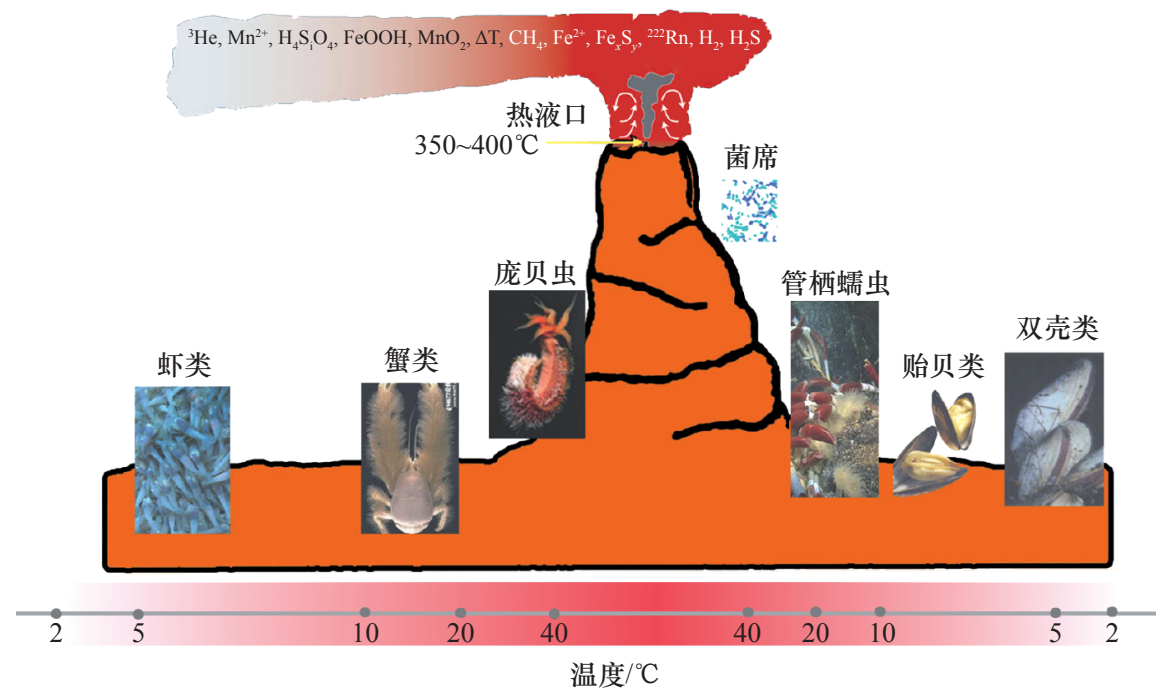

图 1 深海热液区生态系统示意图

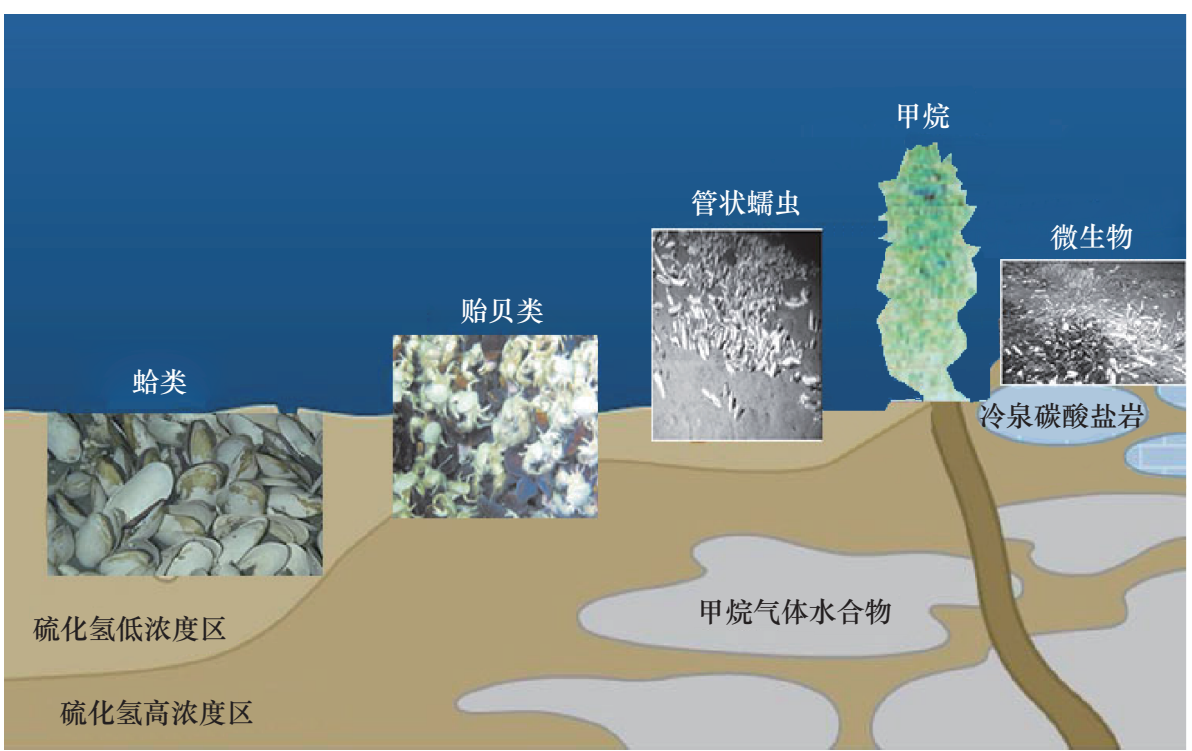

图 2 深海冷泉生态系统示意图 


\section{（三）深海冷水珊瑚生态系统}

冷水珊瑚礁存在于世界各地的大陆架、斜坡、 海底山等, 不仅是深海生态系统的重要组成部分, 而且具有较高的生物多样性和生态资源价值, 同时 也是记录长时间尺度气候变化的良好载体。与浅海 珊瑚依赖与共生光合藻类不同, 深海珊瑚主要以水 中的浮游生物和从表层沉降下来的有机质颗粒为 食。与浅海珊瑚生态系统类似, 冷水珊瑚礁生态系 统也是非常脆弱的, 深海捕鱼、油气开采、深海采 矿, 以及全球气候变化导致的海洋酸化, 都会影响 冷水珊瑚生态系统。相比于热带浅水珊瑚, 深海冷 水珊瑚的研究较少, 但近年来, 随着深海探测技术 的迅猛发展, 冷水珊瑚的研究逐渐增加, 并正在成 为海洋科学研究的新的热点前沿 [16]。

\section{（四）海山生态系统}

海山是深海大洋中的独特生态环境, 广泛存在 于世界各大洋中, 估计有 25000 到 140000 个海山, 覆盖了 $2.88 \times 10^{7} \mathrm{~km}^{2}$ 海洋面积。海山被称为研究海 洋物理和生物过程相互作用的天然实验室 [17]。海 山能够与海洋中不同尺度的流动产生相互作用, 形 成非常复杂的海山多尺度动力过程: 矫正环流、上 升流 (下沉流)、中尺度浴、内波以及小尺度湍流等。 这些多尺度动力过程既相互独立又相互影响, 驱 动着动量、热量以及营养物质的水平和垂直输运, 导致海山区的水体和海底均拥有明显不同于大洋 其他区域的独特生态系统, 其典型特征就是海山 区的浮游生物、游泳生物和底栖生物在生物量、 丰度 $[18,19]$ 、多样性 [20] 等方面往往高于周边的 大洋生态系统和海盆生态系统, 这一系列现象被归 纳为 “海山效应”。但这个观点也受到挑战, 研究 者在 20 年里通过对不同海山的系统调查发现, 基 于叶绿素计算的海山初级生产力仅有几次是高于周 边海域的, 这少数几次的高生产力也可能是被高估 的人为因素, 或者是海山区域发生的短期事件 [21]。 另外一种观点认为, 海山区的高生物量可能并非源 于当地的高级或初级生产力, 而是海流与海山地形 作用带来的悬浮性食物、浮游动物及其捕食者等外 来输入引起的。但是, 科学界都不否认海山生态系 统的高生产力特征必然对海山微生物类群的生物量 及多样性有着显著的影响。海山是否维持比周边海 域较高的生产力仍然是一个海洋之谜。海洋初级生
产力主要取决于营养盐, 但能否积累形成藻华却取 决于水团环流和垂直混合。海山的高生态生产力要 么是海山地形足够浅能够产生上升流, 穿越密度跃 层, 提供深海营养盐到真光层, 要么是海山的物理 海洋过程造成幅聚作用, 将周边的有机物带到海山 形成陷阱效应。总之, 海山区高生产力的原因仍有 待于开展更深入的生态学调查。

\section{（五）深渊生态系统}

深海中深度大于 $6000 \mathrm{~m}$ 的区域称为深渊。人 们曾认为, 由于极端的压力与环境隔绝, 深渊带环 境应该是生命罕至的 “一潭死水”。但是, 近 50 年 来的研究表明, 深渊并不是静止不动, 而是参与深 层气旋环流和大洋深海环流等物理过程的, 具有较 为可观的物质输入，同时也具有丰富的生物多样 性 [22 24]。例如, 在最大深度约 $8000 \mathrm{~m}$ 的阿塔 卡马海沟, 小型底栖生物的密度每平方厘米可达到 6000 余只, 是附近较浅海底平原生物量的 10 倍 [25], 在深度为 $10542 \mathrm{~m}$ 的千岛海沟也有类似的现象发 现 [26]。人们曾在克马德克海沟 $7000 \mathrm{~m}$ 处捕获到体 长达 $35 \mathrm{~cm}$ 的端足类生物, 比其在浅海区的亲缘物种 长出约 10 倍, 这可能与其在深渊缺少捕食者有关 [27]。 深渊由于都在 “碳酸钙补偿深度” 以下，碳酸钙 以溶解态存在, 以碳酸钙为主要结构组分的有孔虫 无法生存, 而科学家却在深渊发现与众不同的有孔 虫种类, 可能与这些有孔虫对深度的适应性进化有 关 [22]。我国科学家利用自主研发的 “天涯号” 和 “海角号” 深渊着陆器, 捕获了马里亚拉海沟 $6000 \mathrm{~m}$ 水深的超深渊狮子鱼, 通过对其形态学分析, 发现 超深渊狮子鱼为适应高压环境, 其骨骼变得非常薄 且具有弯曲能力, 头骨不完全, 肌肉组织也具有很 强的柔韧性。其基因组分析显示, 超深渊狮子鱼视 觉相关的基因发生了大量丢失, 多个与细胞膜稳定 和蛋白结构稳定相关的基因发生了突变, 这些基因 层面的变异可能共同造成了其独特表型, 并帮助其 适应超深渊的极端环境 [28]。这些深渊的特有物种 类群, 也是研究深海生物多样性的宝贵资源。

\section{三、深海生态系统面临的主要挑战}

\section{（一）深海生物多样性下降显著}

2003 年，国际海洋考察理事会（ICES）认为 
大多数 “深水种群可能超出安全生物限度”。例如, 1978-1994 年, 西北大西洋的几个目标物种和非 目标物种的数量下降了 $90 \%$ 以上 [29], 从 20 世纪 60 年代中期到 90 年代, 深海渔业产量每年减少了 $8 \times 10^{5} \sim 1 \times 10^{6} \mathrm{t}[30]$ 。2 20 世纪 90 年代以后, 许多 国家和政府间组织认识到需要加强管理行动, 以保 护脆弱的海洋物种和栖息地, 以促进枯竭种群的恢 复 $[31,32]$ 。然而, 具有低生产能力的深水物种的恢 复可能需要数十年或更长时间 [33]。

由于深海探测技术的局限, 我国在深海生物多 样性调查研究方面还刚刚起步。可喜的是, “十一五” 以来, 我国重点发展海洋技术, 深海开发技术得到 空前发展。目前, 我国已经拥有常压潜水装置、缆 控水下机器人、 $600 \mathrm{~m}$ 无人无缆自治水下机器人等 深海探测装备。值得一提的是, 我国研制的 “蛟龙 号” $7000 \mathrm{~m}$ 载人潜水器, 是目前能够到达海底最深 的载人潜水器, 使我国的深海调查能力可以覆盖世 界 99\% 的洋底。另一台深海潜水器 “深海勇士号”, 也于 2017 年 8 月成功实现载人深潜。值得一提的是, “深海勇士号” 浮力材料、深海锂电池、机械手全 是中国自己研制的, 国产化率达到 95\% 以上。这些 “国之重器” 的成功研发, 展示了我国在深海探测 技术上的飞跃发展, 也为研究和保护深海生物多样 性奠定了基础。在立法层面上, 2016年 5 月 1 日,《中 华人民共和国深海海底区域资源勘探开发法》正式 颁布生效, 该法律将保护深海环境作为专门章节列 出, 对于保护深海物种多样性具有重要意义。这一 立法的颁布实施, 既顺应了国际海底活动发展的大 趋势, 又展示了我国负责任的大国形象。

\section{（二）深海资源开采的生态问题}

深海海底资源勘探和开发必将造福于全人类, 一方面有助于满足社会不断增长的物质与精神需 求, 另一方面还需要可持续发展。在深海海底资源 开发的不同阶段, 均会对海洋环境产生影响。在深 海资源勘探过程中, 大功率的海底勘探机械设施作 业会搅动底层沉积物, 一方面会堵塞大型动物的呼 吸器官, 使其室息死亡; 另一方面, 也会增加海水 中各种矿物质含量, 从而改变海水水质, 对区域内 的珊瑚礁及微生物造成破坏, 致使部分海底生物失 去繁衍和栖息的场所。同时, 在深海勘探中, 伴随 着机械、化学、电解、海洋腐蚀、激光等技术的使
用, 各类污染物会被带入深海。海底矿物加工过程 中产生的大量废弃物被丢弃在海洋中, 大量从事运 输业的船舶在运输过程中产生的污染物被直接排入 海中, 会给深海环境造成污染。由于深海资源通常 处在地质构造较为复杂、断裂活动比较显著和集中 的地区, 深海开采后期很可能诱发地震、引起海底 滑坡等地质灾害。深海资源开采的这些环节, 均会 对深海生态系统产生影响。因此, 必须从可持续发 展原则出发, 不断提高深海生态环境调查评价研究 水平, 增强深海资源开发中的生态环境保护与监控 能力。

《联合国海洋法公约》认为国家主权以外的海 域是全人类的财产, 它的开发必须对全人类有益, 并对海底开采制定了特定的规矩、权力和责任。由 于生物多样性往往集中存在于热点区域, 设置生态 保护区成为一个保护生物多样性和生态系统的有效 工具。因此, 全球海洋和陆地保护区的覆盖面积一 直都在持续增长。海洋保护区的概念于 1962 年在 世界国家公园大会上首次被提出, 1988 年在哥斯 达黎加举行的国际自然保护联盟第十七届全会决议 案中, 明确了海洋保护区的目标在于 “通过建立全 球海洋保护区代表系统, 并对人类利用和影响海洋 环境的活动进行管理, 从而实现长期的保护、恢 复, 明智地了解和开发利用世界海洋生态资源”。 1995 年, 我国有关部门制定了《海洋自然保护区管 理办法》, 以贯彻养护为主、适度开发、持续发展的 方针, 加强海洋自然保护区建设和管理。自 2014 年 以来, 全球海洋方面的保护区面积翻了一倍, 目 前保护区面积已达到 $1.7 \%$ 。《生物多样性公约》秘 书处与联合国环境规划署的世界保护监测中心 (WCMC-UNEP) 和联合国发展计划署 (UNDP) 联 合指出, 到 2020 年, $10 \%$ 的海洋区域, 尤其是生物 多样性热点海域, 应该受到有效的保护和管理 [34]。

\section{（三）陆源污染物的影响}

随着社会经济的发展, 许多有机污染物（例 如滴滴涕、多氯联苯和许多其他杀虫剂、除草剂和 工业化学品等) 随着径流输入、海产养殖、化学 品泄漏、海难事故、大气沉降等方式进入海洋。人 们一度认为, 陆源污染物只会影响到近海海域的 生态系统, 但是, 研究人员发现, 深海鱼类中含有 的上述持久性有机污染物的浓度, 可能比表面居 
住的鱼类高一个数量级, 深海随之被认为是全球持 久有机污染物的最终归宿 [35]。现在深海沉积物中 广泛发现微塑料的分布也可以证明这一现象的普遍 性 [36]。我国学者在 $11000 \mathrm{~m}$ 的马里亚纳海沟挑战 者深渊沉积物中, 发现了大量毒性有机污染物, 其 总浓度甚至高于其他较浅海域沉积物中的含量, 表 明持久性有机污染物已经到达了世界海洋中最深 处。这些污染物对于深海生态系统的长远影响目前 尚无法评估 [37]。

\section{（四）气候变化的影响}

随着全球气温逐渐升高, 海洋的分层情况将更 加稳定, 会减少深海氧气的补充。同时, 温度升高 也会导致海水中氧气溶解度降低 [38 40]。在过去 的 20 年中, 印度洋、大西洋和太平洋的氧气浓度 已经下降, 这些地区有明显的最低氧气带 (OMZ), 伴随着 OMZ 水团的水平和垂直扩张 [41], 深海生 物群落将受到严重影响, 缺氧能够导致生物量和生 物多样性大大减少 [42 44]。另外, 上层海洋的脱 氧还可能导致向深海食物的供应减少, 例如, 加利 福尼亚寒流在氧气浓度较低的时期, 中层水的鱼类 数量显著减少, 从而导致许多深水鱿鱼和深海鱼类 数量下降了约 $60 \%[45,46]$ 。

\section{四、深海生态保护的关键需求和策略}

\section{（一）建立深海生物数据库}

在过去的几十年里, 深海生物多样性研究取得 了快速进步。然而, 依然存在深海研究较为分散、 研究对象集中在个体较大的生物类群上、研究区域 集中在水深较浅的区域等问题。未来可通过战略性 合作, 建立典型深海生态环境、深海生物多样性数 据库。在采样方法上, 需要建立标准的数据采样、 分析与共享机制。在研究对象上, 不仅仅是针对宏 观生物, 利用目前发展较快的分子生物学与宏基因 组技术, 也可以建立微型生物的数据库。在采样设 备上, 利用深海探测设备 (如遥控无人潜水器、载 人深潜器等) 及原位观测设备 (针系基阵、深水滑 翔机等), 可在空间和时间上极大地拓展对深海生 物多样性的认识。同时, 利用数值模拟的方法, 可 以扩大生态信息的空间覆盖范围, 并发展出科学假 设来指导采样方向。通过深海生物多样性数据库的
建立, 可对不同典型海洋环境中生物多样性信息进 行跟踪分析, 并利用这些信息来确定生物多样性的 热点和大规模的生态模式, 分析随时间和空间的物 种迁移, 随温度、盐度和深度发现新的物种, 并比 较物种栖息地等。在此基础之上, 对深海生物多样 性的认识将会更加全面深入, 从而为深海资源开发 与生态系统保护的平衡发展提供依据。

\section{（二）平衡深海资源利用与生态保护的关系}

深海生态系统的特征决定其保护策略会迥异于 浅海生态系统 $[47,48]$ 。目前, 仅有少数的国家和国 际组织, 能够科学地实施深海生态管理、保护和恢 复。在 2007 年和 2008 年的联合国大会上, 深海生 态系统保护问题被提上议程。科学家们必须提供信 息, 以帮助指导保护和可持续管理深海生态系统。 基础生态研究的增加对于协助海洋保护区的设计至 关重要。但是, 不同于陆地生态系统的研究, 深海 生态系统的数据获取与深海探测技术的发展紧密相 关。目前可以做到的是, 将不同的深海生态环境进 行分类, 建立深海生物类群多样性与其栖息地的对 应关系。进而通过生物地理分布模型来预测那些研 究程度较低的深海区域的生态系统变化 [48]。生物 多样性 / 栖息地模型与其他的模型整合, 对于建立 海洋保护区具有很好的指导意义, 从而能够有效地 指导深海资源开发利用 [49]。

随着社会的不断发展, 资源的开发利用与生态 环境保护的矛盾日趋明显, 涉及众多利益相关者, 因此平衡经济和生态保护的考虑不是一项简单的任 务。深海资源的开发利用与生态保护问题同样如此, 深海管理政策的成功依赖于利益相关者的公开信息 交流。管理者需要与资源利用者共同合作, 利用科 学研究提供的信息为依据, 从而可持续地开发利用 深海资源。

\section{（三）发展深海生态理论模型}

岛屿生物地理平衡理论是生态学研究的经典理 论之一, 该理论认为岛屿上的生物种数取决于岛屿 的面积、年龄、生态环境的多样性、拓殖者从来源 地进入岛屿的可能性和来源的丰富性, 以及新种拓 殖的速度和现存种绝灭速度的平衡状况 [50,51]。该 理论的提出, 为设定生物保护区保护生物多样性和 可持续发展平衡提供了理论依据, 为保护生态学奠 
定了科学基础。然而, 该理论目前主要是在陆地和 浅海生态系统中得到验证与应用, 深海生态系统中 的生物多样性, 是否也符合该理论模型, 仍然缺乏 研究。深海中广泛分布的海山、冷泉、热液、鲸落 等生态环境, 类似于上述理论中的各个岛屿, 将 深海中不同的生态环境通过类似的生态理论进行关 联, 建立深海生物多样性受生态环境面积大小、生 态环境地质背景、生态环境水化学特征等因素的调 控作用, 将对深海生物多样性的保护及设立深海生 物保护区具有重要的指导意义。随着我国深海探 测装备的日益发展, 系统而精确的深海生物多样 性调查成为可能, 也为发展深海生态理论模型提 供了机遇。

\section{（四）加快管理对策和法律文书的制定}

最近联合国加快了对国家主权以外的海洋管 理, 正在根据《联合国海洋法公约》就 “国家管辖 范围以外区域海洋生物多样性的养护和可持续利 用” 拟定一份具有法律约束力的国际文书（简称 $B B N J)$ 。其主要内容将包括：国家管辖范围以外区 域海洋生物多样性的养护和可持续利用; 海洋遗传 资源，包括惠益分享问题; 划区管理工具包括海洋 保护区等措施; 环境影响评估; 能力建设和海洋技 术转让。这份文书目前正在讨论中, 一旦形成法律 文件和实施, 将对国家主权以外海域的海洋资源开 发产生巨大影响。因此, 我们不仅仅需要了解开发 海域的生态环境、生物多样性和生态系统, 还需 要发展更为先进的开采技术以减少对生态环境的 伤害。

\section{参考文献}

[1] Corliss J B, Dymond J, Gordon L I, et al. Submarine thermal springs on the Galapagos Rift [J]. Science, 1979, 203(4385): 1073-1083.

[2] Martin W, Baross J, Kelley D, et al. Hydrothermal vents and the origin of life [J]. Nature Reviews Microbiology, 2008, 6(11): 805-814

[3] Weiss M C, Sousa F L, Mrnjavac N, et al. The physiology and habitat of the last universal common ancestor [J]. Nature Microbiology, 2016, 1(9): 16116

[4] Desbruyères D, Segonzac M, Bright M. Handbook of deep-sea hydrothermal vent fauna second edition [M]. Linz: State Museum of Upper Austria, 2006.

[5] Miroshnichenko M L. Thermophilic microbial communities of deep-sea hydrothermal vents [J]. Microbiology, 2004, 73(1): 1-13.
[6] Cavanaugh C M, Wirsen C O, Jannasch H. Evidence for methylotrophic symbionts in a hydrothermal vent mussel (Bivalvia: Mytilidae) from the Mid-Atlantic Ridge [J]. Applied and Environmental Microbiology, 1992, 58(12): 3799-3803.

[7] Minic Z, Hervé G. Biochemical and enzymological aspects of the symbiosis between the deep-sea tubeworm Riftia pachyptila and its bacterial endosymbiont [J]. European Journal of Biochemistry, 2004, 271(15): 3093-3102.

[8] Kashefi K, Lovley D R. Extending the upper temperature limit for life [J]. Science, 2003, 301(5635): 934.

[9] Xie W, Wang F, Guo L, et al. Comparative metagenomics of microbial communities inhabiting deep-sea hydrothermal vent chimneys with contrasting chemistries [J]. ISME Journal, 2011, 5(3): 414-426.

[10] Bourbonnais A, Juniper K, Butterfield D A, et al. Activity and abundance of denitrifying bacteria in the subsurface biosphere of diffuse hydrothermal vents of the Juan de Fuca Ridge [J]. Biogeosciences Discussions, 2012, 9(4): 4177-4223.

[11] 王春生, 杨俊毅, 张东声, 等. 深海热液生物群落研究综述 [J]. 厦 门大学学报(自然科学版), 2006, 45(2): 141-149.

Wang C S, Yang J Y, Zhang D S, et al. A review on deep-sea hydrothermal vent communities [J]. Journal of Xiamen University (Natural Science Edition), 2006, 45(2): 141-149.

[12] Sievert S M, Hügler M, Taylor C D, et al. Sulfur oxidation at deepsea hydrothermal vents [M]. Berlin: Springer, 2008.

[13] Logan G A, Jones A T, Kennard J M, et al. Australian offshore natural hydrocarbon seepage studies, a review and re-evaluation $[\mathrm{J}]$. Marine and Petroleum Geology, 2010, 27(1): 26-45.

[14] Tryon M D, Brown K M. Complex flow patterns through Hydrate Ridge and their impact on seep biota [J]. Geophysical Research Letters, 2001, 28(14): 2863-2866.

[15] 陈忠, 杨华平, 黄奇瑜, 等. 海底甲烷冷泉特征与冷泉生态系统 的群落结构 [J]. 热带海洋学报, 2007, 26(6): 73-82.

Chen Z, Yang H P, Huang Q Y, et al. Characteristics of cold seeps and structures of chemoautosynthesis-based communities in seep sediments [J]. Journal of Tropical Oceanography, 2007, 26(6): 73-82.

[16] 赵美霞, 余克服. 冷水珊瑚礁研究进展与评述 [J]. 热带地理, 2016, 36(1): 94-100.

Zhao M X, Yu K F. A review of recent research on cold-water coral reefs [J]. Tropical Geography, 2016, 36(1): 94-100.

[17] 张均龙, 徐奎栋. 海山生物多样性研究进展与展望 [J]. 地球科 学进展, 2013, 28(11): 1209-1216.

Zhang J L, Xu K D. Progress and prospects in seamount biodiversity [J]. Advances in Earth Science, 2013, 28(11): 1209-1216.

[18] Genin A, Dayton P K, Lonsdale P F, et al. Corals on seamount peaks provide evidence of current acceleration over deep-sea topography [J]. Nature, 1986, 322(6074): 59.

[19] Samadi S, Bottan L, Macpherson E, et al. Seamount endemism questioned by the geographic distribution and population genetic structure of marine invertebrates [J]. Marine Biology, 2006, 149(6): 1463-1475.

[20] de Forges B R, Koslow J A, Poore G. Diversity and endemism of the benthic seamount fauna in the Southwest Pacific [J]. Nature, 2000, 405(6789): 944.

[21] Genin A, Dower J F. Seamount plankton dynamics [M]. UK: 
Blackwell Publishing, 2007.

[22] Todo Y, Kitazato H, Hashimoto J, et al. Simple foraminifera flourish at the ocean's deepest point [J]. Science, 2005, 307(5710): 689.

[23] Itoh M, Kawamura K, Kitahashi T, et al. Bathymetric patterns of meiofaunal abundance and biomass associated with the Kuril and Ryukyu trenches, western North Pacific Ocean [J]. Deep Sea Research Part I: Oceanographic Research Papers, 2011, 58(1): 86-97.

[24] Fujii T, Kilgallen N M, Rowden A A, et al. Deep-sea amphipod community structure across abyssal to hadal depths in the Peru-Chile and Kermadec trenches [J]. Marine Ecology Progress Series, 2013, 492: 125-138.

[25] Danovaroa R, Gambia C, Croceb N D. Meiofauna hotspot in the Atacama Trench, eastern South Pacific Ocean [J]. Deep-Sea Research I, 2002, 49: 843-857.

[26] Schmidt C, Arbizu P M. Unexpectedly higher metazoan meiofauna abundances in the Kuril-Kamchatka Trench compared to the adjacent abyssal plains [J]. Deep-Sea Research II, 2015, 111: 60-75.

[27] Jamieson A J, Lacey N C, Lorz A N, et al. The supergiant amphipod Alicella gigantea (Crustacea: Alicellidae) from hadal depths in the Kermadec Trench, SW Pacific Ocean [J]. Deep-Sea Research II, 2013, 92: 107-113.

[28] Wang K, Shen Y, Yang Y, et al. Morphology and genome of a snailfish from the Mariana Trench provide insights into deep-sea adaptation [J]. Nature Ecology \& Evolution, 2019, 3: 823-833.

[29] Devine J A, Baker K D, Haedrich R L. Fisheries: Deep-sea fishes qualify as endangered [J]. Nature, 2006, 439(7072): 29.

[30] Koslow J A. The silent deep: The discovery, ecology, and conservation of the deep sea [J]. Oceanography, 2007, 23(1): 228.

[31] Clark M R, Vinnichenko V I, Gordon J D, et al. Large-scale distant-water trawl fisheries on seamounts [J]. Seamounts: Ecology, Fisheries, and Conservation, 2007, 12: 361-399.

[32] Watson R, Kitchingman A, Cheung W W. Catches from world seamount fisheries [M]. UK: Blackwell Publishing, 2007.

[33] Baker K D, Devine J A, Haedrich R L. Deep-sea fishes in Canada's Atlantic: Population declines and predicted recovery times $[\mathrm{J}]$. Environmental Biology of Fishes, 2009, 85(1): 79.

[34] UNEP-WCMC, IUCN. 2018 United Nations list of protected areas. Supplement on protected area management effectiveness [R]. Cambridge: UNEP-WCMC, IUCN, 2018.

[35] Takahashi S, Tanabe S, Kubodera T. Butyltin residues in deep-sea organisms collected from Suruga Bay, Japan [J]. Environmental Science \& Technology, 1997, 31(11): 3103-3109.

[36] Van Cauwenberghe L, Vanreusel A, Mees J, et al. Microplastic pollution in deep-sea sediments [J]. Environmental Pollution,
2013, 182: 495-499.

[37] Dasgupta S, Peng X T, Chen S, et al. Toxic anthropogenic pollutants reach the deepest ocean on Earth [J]. Geochemical Perspectives Letters, 2018 (7): 22-26.

[38] Sarmiento J L, Hughes T M, Stouffer R J, et al. Simulated response of the ocean carbon cycle to anthropogenic climate warming [J]. Nature, 1998, 393(6682): 245.

[39] Matear R, Hirst A. Long-term changes in dissolved oxygen concentrations in the ocean caused by protracted global warming [J]. Global Biogeochemical Cycles, 2003, 17(4): 1125.

[40] Shaffer G, Olsen S M, Pedersen J O P. Long-term ocean oxygen depletion in response to carbon dioxide emissions from fossil fuels [J]. Nature Geoscience, 2009, 2(2): 105.

[41] Whitney F A, Freeland H J, Robert M. Persistently declining oxygen levels in the interior waters of the eastern subarctic Pacific [J]. Progress in Oceanography, 2007, 75(2): 179-199.

[42] Wishner K, Levin L, Gowing M, et al. Involvement of the oxygen minimum in benthic zonation on a deep seamount [J]. Nature, 1990, 346(6279): 57.

[43] Gibson R, Atkinson R. Oxygen minimum zone benthos: Adaptation and community response to hypoxia [J]. Oceanography and Marine Biology, 2003, 41: 1-45.

[44] Stramma L, Schmidtko S, Levin L A, et al. Ocean oxygen minima expansions and their biological impacts [J]. Deep Sea Research Part I: Oceanographic Research Papers, 2010, 57(4): 587-595.

[45] Koslow J A, Auster P, Bergstad O A, et al. Biological communities on seamounts and other submarine features potentially threatened by disturbance [M]. New York: United Nations, 2016.

[46] Koslow J A, Goericke R, Lara-Lopez A, et al. Impact of declining intermediate-water oxygen on deepwater fishes in the California Current [J]. Marine Ecology Progress Series, 2011, 436: 207-218.

[47] Glover A G, Smith C R. The deep-sea floor ecosystem: Current status and prospects of anthropogenic change by the year 2025 [J]. Environmental Conservation, 2003, 30(3): 219-241.

[48] Clark M R, Rowden A A, Schlacher T, et al. The ecology of seamounts: Structure, function, and human impacts [J]. Annual Review of Marine Science, 2010, 2: 253-278.

[49] Leathwick J, Moilanen A, Francis M, et al. Novel methods for the design and evaluation of marine protected areas in offshore waters [J]. Conservation Letters, 2008, 1(2): 91-102.

[50] MacArthur R H, Wilson E O. An equilibrium theory of insular zoogeography [J]. Evolution, 1963, 17(4): 373-387.

[51] MacArthur R H, Wilson E O. The theory of island biogeography [M]. New Jersey: Princeton University Press, 1967. 